\title{
Evaluation of functional outcome of displaced fracture neck of femur in elderly treated with cemented bipolar prosthesis by modified Harris hip score
}

\author{
Shivakumar B. Kerakkanavar, Deepak P. Kaladagi*, Nagesh B. Sanakal, \\ Pundaleekappa S. Kaladagi, Praveenkumar A. Hongal
}

Department of Orthopedics, SNMC and HSK, Bagalkot, Karnataka, India

Received: 17 January 2021

Revised: 17 February 2021

Accepted: 04 March 2021

*Correspondence:

Dr. Deepak P. Kaladagi,

E-mail: drdeepakkortho@gmail.com

Copyright: (c) the author(s), publisher and licensee Medip Academy. This is an open-access article distributed under the terms of the Creative Commons Attribution Non-Commercial License, which permits unrestricted non-commercial use, distribution, and reproduction in any medium, provided the original work is properly cited.

\begin{abstract}
Background: The current research was conducted to determine the functional outcome of the displaced fracture neck of femur in elderly patients treated with cemented bipolar hip prosthesis.

Methods: The present research was a prospective study of 44 cases of displaced fracture neck of femur admitted to our institute between October 2017 and October 2019. Cases were chosen on the basis of inclusion and exclusion criteria. Cases were surgically treated with cemented bipolar hip hemiarthroplasty and functional findings were recorded with modified Harris hip score.

Results: In our series of 44 cases there were 30 females and 14 males, with a maximum age of 92 years, minimum age of 65 years, and the average age was 72.72 years. At one-year follow-up, the average modified Harris hip score was $86.75 \%$ (maximum score of 95 and a minimum score of 66), overall, 20 patients (45.46\%) achieved excellent, 16 patients $(36.36 \%)$ achieved good, 5 patients $(11.36 \%)$ achieved fair and 3 patients $(6.82 \%)$ achieved poor results. $81.82 \%$ of the patients returned to the pre-fracture level of activity and independent ambulation. Patients had few complications like limb length discrepancy, $36.3 \%$ of patients had limb lengthening between 1 to $1.5 \mathrm{~cm}$.

Conclusions: In elderly patients with displaced neck femur fractures, cemented bipolar hip prosthesis provides good functional outcome. However further study for a longer period in a larger sample with a direct comparison between the cemented versus uncemented groups is required.
\end{abstract}

Keywords: Bipolar prosthesis, Femur neck fracture, Harris hip score

\section{INTRODUCTION}

Hip fracture is a common injury, with increasing life expectancy worldwide, the number of elderly people is rising and incidence of hip fractures is expected to rise from 1.66 million in 1990 to 6.26 million by 2050 . According to the Swedish national hip fracture registry, intracapsular fractures of the femoral neck represent 53\% of all hip fractures, $33 \%$ of which are un-displaced and $67 \%$ of which are displaced. ${ }^{1}$ The purpose of the treatment of these fractures is to mobilize the patient as soon as possible and to become independent in order to meet their basic daily needs.

The burden of this fracture and its implications continue to increase, as our society is rapidly becoming a geriatric society. ${ }^{2}$ The aim of the treatment is to restore pre-fracture function without associated morbidity. ${ }^{3}$ However, the treatment of displaced femoral neck fractures in the elderly has been problematic. Open reduction and the internal 
fixation of such fractures have poor outcomes, including increased the incidence of non-union and avascular necrosis. $^{4}$

Fracture in the neck of the femur is one of the most common injuries in the elderly population, resulting in morbidity and mortality among the elderly. ${ }^{5}$ This fracture presents an epidemic problem for the healthcare system and the population in general. In elderly patients with osteoporotic bones, a trivial fall is the cause of hip fractures in about $90 \%$ of cases. ${ }^{6}$

A typical patient with fractured femur neck will be elderly with severe osteoporosis and co-morbidities. ${ }^{7-8}$ These patients have always been a significant concern to the orthopedic surgeon and remain an unexplained mystery in terms of management.

Bipolar prosthesis steadily eliminates the use of unipolar prosthesis due to its superior benefits, having higher percentage of acceptable results like less dislocations, less postoperative discomfort, a wider range of movements, a quicker return to unassisted activity, and a reduced incidence of acetabular erosion.

The current study involves surgical treatment of displaced fracture neck of femur with bipolar hip prosthesis and its evaluation with modified Harris hip score. ${ }^{9}$

\section{METHODS}

\section{Source of data}

It was prospective case study. Traumatic, displaced fracture neck of the femur in the elderly (> 65 years) presenting to our institute from October 2017 to October 2019 was included in the study.

\section{Data collection}

Data were obtained on the basis of a comprehensive history, clinical and radiological assessment of the patient. Postoperative assessment was done both clinically and radiologically. Out of the 44 cases, all patients were eligible for follow-up until one year, which was considered a basic pre-requisite for study inclusion.

\section{Inclusion criteria}

It included the patients with displaced fracture neck of femur in more than 65 years of age, pre fracture independent walking, absence of severe cognitive function and good cardiopulmonary assessment.

\section{Exclusion criteria}

Patients who had osteoarthritis of the hip, rheumatoid arthritis, mental illness, drug abuse, alcohol abuse and pathological fracture were excluded from the study.
Once the patient was admitted to the hospital, clinical and radiological investigations were carried out and all the critical details of those who met the inclusion criteria were reported in the proforma prepared for this review. After having anesthetic fitness for the surgery, all patients have been operated with posterior hip approach. Post-operative radiograph was taken and all patients were assessed using proforma to read the variables, such as weight-bearing, hip range of motion, postoperative thigh pain and based on the modified Harris hip score, the outcome of the hip function was evaluated. Consent was obtained by all patients involved and institutional ethical clearance was obtained for study. Patients were for followed-up at 6 weeks, 3 months, 6 months, and 1 year after the surgery.

\section{Statistical analysis}

The data collected was entered and analyzed in the MS excel sheet. Percentage and proportions were used to determine the functional outcome of the displaced fracture of the femur in elderly patients treated with cemented bipolar hip prosthesis by modified Harris hip score.

\section{RESULTS}

In Table 1, shows patients aged 65-74 years were more (68.18) with an average age of 72.72 years. The youngest patient in the sample was 65 years old and the oldest was 92 years old.

Table 1: Age distribution.

\begin{tabular}{|lll|}
\hline Age (years) & Frequency & Percentage $(\%)$ \\
\hline $\mathbf{6 5 - 7 4}$ & 30 & 68.18 \\
\hline $\mathbf{7 5 - 8 4}$ & 13 & 29.54 \\
\hline $\mathbf{8 5}$ & 01 & 02.28 \\
\hline Total & 44 & 100 \\
\hline
\end{tabular}

Table 2: Sex distribution.

\begin{tabular}{|lll|}
\hline Sex & Frequency & Percentage $(\%)$ \\
\hline Male & 14 & 31.82 \\
\hline Female & 30 & 68.18 \\
\hline Total & 44 & 100 \\
\hline
\end{tabular}

Table 2, indicates the pattern of sex distribution of patients in the sample. The majority of patients were found to be female $(68.18 \%)$.

Table 3: Mode of injury.

\begin{tabular}{|lll|}
\hline Mode of injury & Frequency & Percentage $(\%)$ \\
\hline Slipping & 37 & 84.10 \\
\hline $\begin{array}{l}\text { Fall from } \\
\text { height }\end{array}$ & 07 & 15.90 \\
\hline Total & 44 & 100 \\
\hline
\end{tabular}

Table 3, indicates the majority of patients sustained fracture due to a trivial trauma, i.e., slipping by $84.10 \%$. 
Table 4: Singh's grade of proximal femur.

\begin{tabular}{|lll|}
\hline Singh's index & Frequency & Percentage $(\%)$ \\
\hline Grade-3 & 14 & 31.82 \\
\hline Grade-4 & 16 & 36.36 \\
\hline Grade-5 & 14 & 31.82 \\
\hline Total & 44 & 100 \\
\hline
\end{tabular}

Table 4 , shows grade 4 trabecular pattern of proximal femur is seen in most of cases in our study i.e., $36.36 \%$.

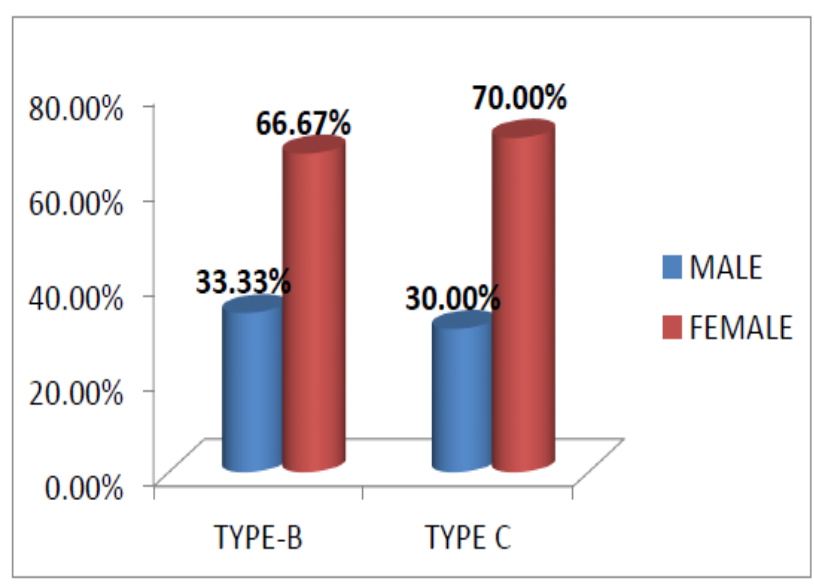

Figure 1: Distribution of femoral canal diameter between male and female.

Figure 1 shows female femoral canal diameter is more (66.67\% Dorr's-B and 70\% Dorr's-C) compared to male patients in our study.

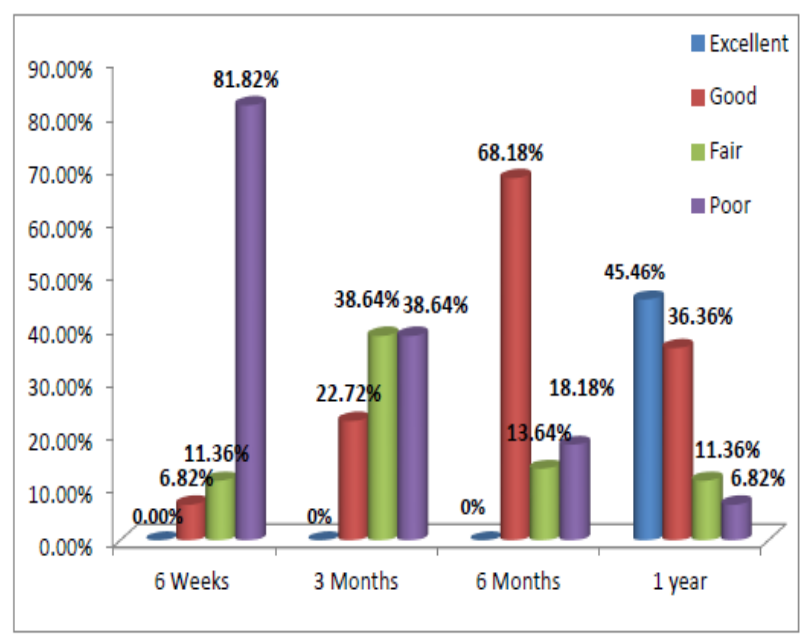

Figure 2: Clinical evaluation of all patients were done at 6 weeks, 3 months, 6 months and 1 year after the day of surgery with modified Harris hip score.

Figure 2 shows $81.82 \%$ of patients had poor functional results at 6 weeks of follow-up. After 3 months of followup, patient had $22.72 \%$ of good outcomes and poor outcomes fell significantly to $38.64 \%$. At the end of 6 months functional outcome improved and $68.18 \%$ of patients registered a good result. At the end of 1 year of follow-up, patients could be grouped as $45.46 \%$ excellent, $36.36 \%$ good, $11.36 \%$ fair and $6.82 \%$ poor scoring.

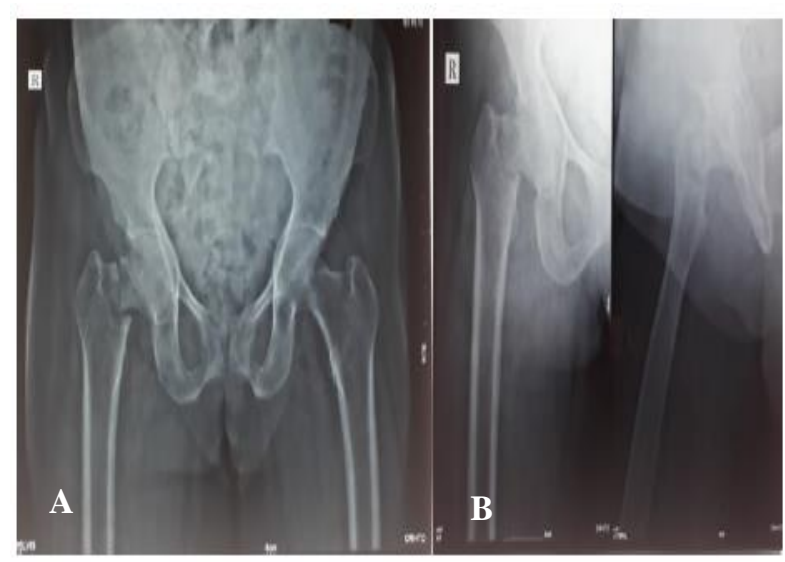

Figure 3 (A and B): Pre-operative radiograph.

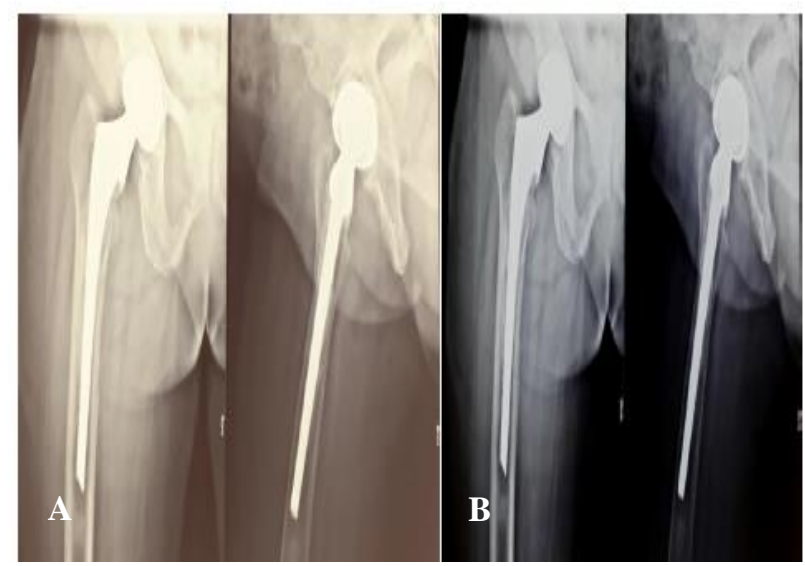

Figure 4: Follow-up (A) at six months (B) at one-year radiograph.

\section{DISCUSSION}

The intracapsular fracture of the proximal femur is one of the common fractures of the elderly. ${ }^{10}$ Owing to the geriatric age and low socio-economic status of patients with osteoporosis, co-morbidities such as type 2 diabetes, hypertension, ischemic heart disease, decreased vision and increased prevalence of minor injuries raise the incidence and complicate the treatment of these fractures. This high incidence is due to weak bones and increased incidence of trivial trauma. ${ }^{10}$

The mean age of the patients in this sample was 72.72 years, the youngest 65 years and the oldest was 92 years old. As in other study, the present research also recorded a higher number of females, i.e., $68.18 \%$ who had a fracture femur neck compared to the male population of $31.82 \% .^{10}$ Elderly females are more likely to fracture the neck of the femur due to osteoporosis (postmenopausal condition). ${ }^{10}$ 
The majority $(84.10 \%)$ of our patients in the study were injured due to trivial trauma such as slipping at bathroom. This is a very common condition in the elderly community, where vision impairment and lack of neuromuscular coordination results in fall. Many of these incidents can be listed as indirect trauma. Other minority $(15.90 \%)$ of patients were injured due to a fall from height.

In our study the majority of patients (25) had a type III garden fracture $(56.82 \%)$ and 19 patients $(43.18 \%)$ had a type IV garden fracture. Even in a comparative analysis by Krishnan et al, among the effects of cemented and uncemented bipolar prosthesis, 29 patients had garden IV, while 5 patients had a garden III fracture. ${ }^{11}$ However, there are no major improvements in the outcomes of the forms of fracture and displacement. ${ }^{11}$

All patients received regular follow-up at 6 weeks, 3 months, 6 months and 1 year of post-surgery. Functional results were measured using the modified Harris hip score system. Pain after hemiarthroplasty is a big concern. Hinchey et al reported that "A total of 294 patients had hemiarthroplasty, 22 patients had pain in the early postoperative period and they could not find a definitive reason for the pain. ${ }^{12}$ Ford stated that the causes of pain may be due to inflammation, improper prosthetic seating, metal corrosion and tissue reactions, improper size of the femoral head, contractures and periarticular ossification. ${ }^{13}$ In our study, 2 patients had pain in the groin on final follow up. However, these patients were encouraged for physiotherapy exercises and were reassured about the condition, along with analgesics were prescribed and advised to be used only when the pain was unbearable.

In our study, the final modified Harris hip score as evaluated at 6 weeks after discharge shows, 36 patients $(81.82 \%)$ had poor functional outcome results. At 3 months follow up functional outcome improved with $38.64 \%$ fair results, $22.72 \%$ good results and poor results decreased dramatically from $81.82 \%$ to $38.64 \%$. No one had excellent results at 3 months follow up. At six months follow functional outcome improved and $68.18 \%$ of patients show good results. In one-year follow-up the average score was $86.75 \%$ with a maximum score of 95 and a minimum score of 66 . Overall, 20 patients $(45.46 \%)$ achieved excellent results, 16 patients $(36.36 \%)$ achieved Good results, 5 patients $(11.36 \%)$ achieved fair results and 3 patients $(6.82 \%)$ achieved poor results. $81.82 \%$ of patients returned to pre fracture level of activity. Our results are comparable with standard studies like the Moshein et al study and the Lestrange study. ${ }^{14,15}$

Radiologically post-operative reduction of bipolar prosthesis assessed. All bipolar heads are positioned in the acetabulum properly. Sinking of prosthesis not seen may be due to adequate bone cement and holding capability. In one case prosthesis was placed in slight valgus but, its significance not present in the outcome. No signs of heterotopic ossification. As the duration of follow-up is less, we didn't find any signs of acetabular erosions and sclerosis. No one had a periprosthetic fracture.

Our study is not without its shortcomings. Firstly, our duration of follow-up of 1 year is very less in assessing the longevity and functional endurance of the prosthesis used. Just 44 patients have been included in the study. Not all surgeries were performed by a single surgeon.

\section{Limitations}

Limitation of the study included a small sample size of 44 patients and a short follow up 1 year.

\section{CONCLUSION}

Female predominance is common in hip fractures. Most of the fracture femur necks were due to trivial fall. Femoral canal diameter is wider in female than male. Proximal femoral trabeculations deteriorate as age rises. Garden type 3 fractures were the most common pattern of the neck of femur fracture observed which accounted for $56.82 \%$. The final functional outcome was excellent in $45.46 \%$ of the patients.

\section{Funding: No funding sources Conflict of interest: None declared}

Ethical approval: The study was approved by the institutional ethics committee

\section{REFERENCES}

1. Thorngren KG, Hommel A, Norrman PO, Thorngren $\mathrm{J}$, Wingstrand $\mathrm{H}$. Epidemiology of femoral neck fractures. Injury. 2002;33(3):C1-7.

2. Swiontkowski MF. Intracapsular fractures of the hip. J Bone Joint Surg Am. 1994;76(1):129-38.

3. Iorio R, Healy WL, Lemos DW, Appleby D, Lucchesi CA, Saleh KJ. Displaced femoral neck fractures in the elderly: outcomes and cost-effectiveness. Clin Orthop Relat Res. 2001;(383):229-42.

4. Lu-Yao GL, Keller RB, Littenberg B, Wennberg JE. Outcomes after displaced fractures of the femoral neck. A meta-analysis of one hundred and six published reports. J Bone Joint Surg Am. 1994;76(1):15-25.

5. Parker MJ. Fractures of the neck of the femur. Trauma. 2008;10(1):43-53.

6. Schmidt AH, Leighton R, Parvizi J, Sems A, Berry DJ. Optimal arthroplasty for femoral neck fractures: is total hip arthroplasty the answer? J Orthop Trauma. 2009;23(6):428-33.

7. Hopley C, Stengel D, Ekkernkamp A, Wich M. Primary total hip arthroplasty versus Prosthesis for displaced intracapsular hip fractures in the older patient systematic review. BMJ. 2010;340:c2332.

8. Hedbeck CJ, Enocson A, Lapidus G, Blomfeldt R, Törnkvist H, Ponzer S et al. Comparison of bipolar hemiarthroplasty with total hip arthroplasty for displaced femoral neck fractures: a concise four-year 
follow-up of a randomized trial. J Bone Joint Surg Am. 2011;93(5):445-50.

9. Kumar P, Sen R, Aggarwal S, Agarwal S, Rajnish RK. Reliability of Modified Harris Hip Score as a tool for outcome evaluation of Total Hip Replacements in Indian population. J Clin Orthop Trauma. 2019;10(1):128-30.

10. Marya SK, Thukral R, Singh C. Prosthetic replacement in femoral neck fracture in the elderly: results and review of the literature. Indian J Orthop. 2008;42(1):61-7.

11. Krishnan H., Yoon TR., Park KS. Bipolar Hemiarthroplasty in patients presenting with displaced intracapsular femoral neck fractures-A Comparison of cemented and uncemented prosthesis placement. Malaysian Orthop J. 2010;4(1):25-31.

12. Hinchey and Day. Primary prosthetic replacement in fresh femoral neck Fractures. J Bone Joint Surg. 1960;42B:633-40.
13. Ford LEM. Use of Moore self-locking Vitallium prosthesis in acute fractures of the femoral neck. J Bone Joint Surg. 1965;47A:832-41.

14. Moshein J, Alter AH, Elconin KB, Adams WW Jr, Isaacson J. Transcervical fractures of the hip treated with the Bateman bipolar prosthesis. Clin Orthop Relat Res. 1990;(251):48-53.

15. Lestrange NR. Bipolar arthroplasty for 496 hip fractures. Clin Orthop Relat Res. 1990;(251):7-19.

Cite this article as: Kerakkanavar SB, Kaladagi DP, Sanakal NB, Kaladagi PS, Hongal PA. Evaluation of functional outcome of displaced fracture neck of femur in elderly treated with cemented bipolar prosthesis by modified Harris hip score. Int J Res Orthop 2021;7:561-5. 